\title{
Comparison of teneligliptin with sitagliptin as an add on to metformin in patients of type 2 diabetes mellitus: an observational study
}

\author{
S. V. Dange, Nimish S. Narkar*, Pratik Rane, Sayan Das, \\ Vishwadeep Madrewar, Revati Kothari
}

Department of Pharmacology, Dr. D. Y. Patil Vidyapeeth, Pune, Maharashtra, India

\author{
Received: 23 April 2020 \\ Revised: 12 May 2020 \\ Accepted: 13 May 2020 \\ *Correspondence: \\ Dr. Nimish S. Narkar \\ Email: dr.nimishnarkar@gmail.com
}

Copyright: ( $)$ the author(s), publisher and licensee Medip Academy. This is an open-access article distributed under the terms of the Creative Commons Attribution Non-Commercial License, which permits unrestricted non-commercial use, distribution, and reproduction in any medium, provided the original work is properly cited.

\begin{abstract}
Background: Teneligliptin is a new dipeptidyl peptidase-4 (DPP-4) inhibitor, available in India. It has been widely prescribed in type 2 diabetes mellitus (T2 DM) due to its low cost. However, there are few studies comparing it with other DPP-4 inhibitors. The objective of this study is to compare the efficacy of teneligliptin with sitagliptin in patients of T2 DM.

Methods: Patients of T2 DM, attending the OPD of a hospital during the period of January to August 2017 were scrutinized. Those uncontrolled on metformin monotherapy (1 g/day) were selected and were administered either sitagliptin (100 mg/day) or teneligliptin $(20 \mathrm{mg} / \mathrm{day})$ in addition to metformin. Base-line clinical features (age, sex, body-weight, BP, pulse rate etc.) and laboratory parameters (hemogram, fasting blood sugar and postprandial blood sugar, HbA1c, serum creatinine etc.) were recorded initially and at the end of three months. Side effects were assessed with the help of a questionnaire. The data obtained were analyzed by student's t-test. $\mathrm{P}<0.05$ was considered as statistically significant.

Results: 35 and 32 patients received sitagliptin and teneligliptin respectively. After 12 weeks of therapy, FBS, PPBS and $\mathrm{HbA} 1 \mathrm{c}$ significantly reduced in both the groups as compared to base-line values. Both drugs were well tolerated. There was no significant difference in the glycemic parameters between the two groups at the end of the study.

Conclusions: Teneligliptin significantly improved glycemic control in patients with T2 DM when prescribed as an add on to metformin. It was equally effective when compared to sitagliptin. As teneligliptin is less costly than other gliptins, it may be considered as a good cost-effective option as an add on to patients of T2 DM uncontrolled on metformin monotherapy.
\end{abstract}

Keywords: Teneligliptin, Sitagliptin, Metformin, T2 DM

\section{INTRODUCTION}

Diabetes mellitus is a spectrum of metabolic disorders, which arise from multiple pathogenic mechanisms, all resulting in hyperglycemia. Hence its management requires continuous medical care with multifactorial riskreduction strategies beyond glycemic control. ${ }^{1}$ There are now a wide variety of treatment options for hyperglycemia that target different processes involved in glucose dysregulation. ${ }^{2}$

Dipeptidyl peptidase-4 (DPP-4) inhibitors is a new class of antidiabetic agents that show favourable results in improving glycemic control with minimal risk of hypoglycemia and weight gain. DPP-4 inhibitors have favorable side effect profile. ${ }^{3,4}$ It is recommended as second line drug after inadequate control with metformin 
and therapeutic life style interventions or may be used initially in case of metformin intolerance or contraindications. ${ }^{5}$ Various DPP-4 inhibitors are available in our country viz. sitagliptin, vildagliptin, linagliptin, saxagliptin etc.

Teneligliptin is a new DPP-4 inhibitor, available in India, which is widely prescribed due to its low cost. However, there are few head to head comparative studies among the DPP-4 inhibitors. Hence, this study was conducted to compare the efficacy of teneligliptin with that of sitagliptin.

\section{Aim}

To compare the efficacy and safety of teneligliptin with that of sitagliptin in patients of type 2 diabetes mellitus uncontrolled on metformin.

\section{METHODS}

The study was conducted in patients attending the OPD of Dhanashree Hospital, New Sangavi, Pune from January to August 2017. Patients of type 2 diabetes mellitus (T2 DM) (<5 years duration), in the age group of 18-65 years and not controlled on metformin monotherapy $(1 \mathrm{~g} / \mathrm{d})$ were selected. Written informed consent was obtained prior to inclusion in the study. These patients were given either sitagliptin $100 \mathrm{mg} / \mathrm{d}$ or teneligliptin $20 \mathrm{mg} / \mathrm{d}$. Other drugs like anti-hypertensives, anti-dyslipidemics etc. were continued. No other antidiabetic drug was given. Criteria for exclusion were patients with T2 DM for more than 5 years, T1 DM, severe cardiac, hepatic or renal disease and pregnant women.
Prior institutional ethics committee clearance was obtained. Both drugs were administered before breakfast. Metformin (1 g SR) was continued after dinner. Base-line clinical features (age, sex, body weight, blood pressure, pulse rate etc.) and laboratory parameters (blood sugar level- fasting and post-prandial, HbAlc, serum creatinine etc.) were recorded initially and at the end of three months. Side effects were assessed with the help of a questionnaire.

The data obtained were analyzed by student's ' $\mathrm{t}$ ' test. $\mathrm{p}<0.05$ was considered as statistically significant.

\section{RESULTS}

Study was conducted over the period of eight months from January to August 2017. Total 74 patients of T2 DM, meeting the inclusion criteria were enrolled in the study. 38 patients received sitagliptin and 36 were treated with teneligliptin. However, three patients from sitagliptin group and four from teneligliptin group did not attend the follow up. Thus, 35 patients were treated with sitagliptin, while 32 patients received teneligliptin. Baseline clinical characteristics are mentioned in (Table 1). There was no significant difference between the two groups at baseline. After 12 weeks of therapy, there was significant $(\mathrm{p}<0.05)$ reduction in fasting blood sugar (FBS), postprandial blood sugar (PPBS) and glycated hemoglobin (HbA1c) levels in both the groups as compared to base-line values (Table 2). However, there was no significant difference between the two groups. Both drugs were well tolerated, the side effects were minor and did not require discontinuation of treatment (Table 3).

Table 1: Baseline clinical and laboratory characteristics of the patients.

\begin{tabular}{|c|c|c|}
\hline Variables & Sitagliptin and metformin ( $\mathrm{n}=35)$ & Teneligliptin and metformin $(\mathrm{n}=32)$ \\
\hline Age (y) & $53.5 \pm 7.1$ & $58.1 \pm 8.6$ \\
\hline $\operatorname{Sex}(M / F)$ & $20 / 15$ & $20 / 12$ \\
\hline Body-weight (kg) & $66.5 \pm 10.7$ & $64.7 \pm 10.4$ \\
\hline Height (cm) & $152.5 \pm 8.6$ & $150.2 \pm 8.3$ \\
\hline BMI $\left(\mathrm{kg} / \mathrm{m}^{2}\right)$ & $28.42 \pm 3.5$ & $28.76 \pm 3.2$ \\
\hline Duration of DM (years) & $3.5 \pm 0.8$ & $3.2 \pm 0.7$ \\
\hline BP mmHg (SBP) & $152 \pm 26$ & $160 \pm 25$ \\
\hline BP mmHg (DBP) & $95 \pm 14$ & $97 \pm 17$ \\
\hline FBS (mg/dl) & $158.4 \pm 30.5$ & $156.2 \pm 32.3$ \\
\hline 2h PPBSL (mg/dl) & $241.1 \pm 57.2$ & $238.4 \pm 55.4$ \\
\hline $\mathrm{HbA}_{1 \mathrm{c}}(\%)$ & $7.54 \pm 0.86$ & $7.52 \pm 0.77$ \\
\hline
\end{tabular}

Table 2: Glycemic parameters at baseline and 12 weeks in the two groups.

\begin{tabular}{|llllll|}
\hline \multirow{2}{*}{ S. no. } & Parameter & Sitagliptin and metformin $(\mathbf{n}=\mathbf{3 5})$ & \multicolumn{2}{l|}{ Teneligliptin and metformin $(\mathbf{n = 3 2})$} \\
\hline $\mathbf{1}$ & FBS $(\mathrm{mg} / \mathrm{dl})$ & Baseline & $\mathbf{1 2}$ weeks & Baseline & $\mathbf{1 2}$ weeks \\
\hline $\mathbf{2}$ & $2 \mathrm{~h} \mathrm{PPBSL}(\mathrm{mg} / \mathrm{dl})$ & $158.4 \pm 30.5$ & $135.10 \pm 25.10^{*}$ & $156.2 \pm 32.3$ & $135.60 \pm 23.3^{*}$ \\
\hline $\mathbf{3}$ & $\mathrm{HbA}_{\mathrm{lc}}(\%)$ & $241.1 \pm 57.2$ & $192.9 \pm 38.3^{*}$ & $238.4 \pm 55.4$ & $195.3 \pm 37.4^{*}$ \\
\hline
\end{tabular}

$* \mathrm{P}<0.05$ as compared to base-line value in the same group. No significant difference in the glycemic parameters between the two groups. 
Table 3: Number of patients complaining of the sideeffects of the drugs of both groups.

\begin{tabular}{|l|l|l|}
\hline Side effects & $\begin{array}{l}\text { Sitagliptin and } \\
\text { metformin } \\
(\mathbf{n}=35)\end{array}$ & $\begin{array}{l}\text { Teneligliptin } \\
\text { and } \\
\text { metformin } \\
(\mathbf{n}=32)\end{array}$ \\
\hline Incidence & 5 & 5 \\
\hline Dizziness & 3 & 2 \\
\hline Itching/rash & 2 & 2 \\
\hline Nausea/vomiting & 1 & 2 \\
\hline $\begin{array}{l}\text { Urinary tract } \\
\text { infections }\end{array}$ & 2 & 1 \\
\hline
\end{tabular}

\section{DISCUSSION}

In this study, teneligliptin significantly improved glycemic control in patients with T2DM, when prescribed as an add on to metformin. Kim et al studied the efficacy of teneligliptin added to metformin in Korean patients with type 2 diabetes mellitus. ${ }^{6}$ Similar to our study these patients were not controlled with metformin. However, this was a 16 weeks study and patients were given teneligliptin or placebo in $2: 1$ ratio. They found significant reduction in the glycemic parameters with teneligliptin $(n=136)$ treatment as compared to placebo. ${ }^{6}$ Our findings are similar to the results of this study. Recently, Ghosh et al studied the real-world efficacy of teneligliptin in T2 DM patients in our country. ${ }^{7}$ This study included patients treated with teneligliptin alone as well as in combination with other anti-diabetic drugs they noted that at the end of 3 months, there was significant improvement in all the glycemic parameters like FPG, PPG and $\mathrm{HbA}_{1 \mathrm{c}}$. The reduction in $\mathrm{HbA}_{1 \mathrm{c}}$ was $1.07 \pm 0.83$. We observed the reduction in $\mathrm{HbA} 1_{c}$ as 0.60 . This difference may be because of shorter duration (12 weeks) of our study as compared to longer duration of their study as well as due to the large population $(n=4305)$ of their study. Sharma et al studied the efficacy and safety of the addition of teneligliptin in inadequately controlled T2 DM patients with metformin monotherapy in a randomized, double-blind, placebo-controlled, parallelgroup, phase III study $(\mathrm{n}=204) .{ }^{8}$ This study showed a significant reduction in the FPG and $\mathrm{HbA}_{1 \mathrm{c}}$. Our findings are similar to the results of this study.

This is the first study on direct comparison between two gliptins in treatment of patients of T2 DM in real world situation. Thus, it was found that teneligliptin is equally effective and well tolerated as compared to sitagliptin.

\section{CONCLUSION}

Advantages of teneligliptin are that it is less costly than other gliptins hence good patient compliance and no dose modification required in patients with renal impairment. Hence, it should be considered as a good option in patients of T2 DM whose glycemic parameters are uncontrolled on metformin monotherapy. However, this is a small single-centre observational study hence further studies are necessary.

Funding: No funding sources Conflict of interest: None declared

Ethical approval: The study was approved by the Institutional Ethics Committee

\section{REFERENCES}

1. Introduction: Standards of Medical Care in Diabetes2018. Diabetes Care. 2018;41(1):1-2.

2. Nathan DM. Diabetes: advances in diagnosis and treatment. JAMA. 2015;314:1052-62.

3. Gallwitz B. Clinical Use of DPP-4 Inhibitors. Front Endocrinol (Lausanne). 2019;10:389.

4. Bailey T. Options for combination therapy in type 2 diabetes: comparison of the ADA/EASD position statement and AACE/ACE algorithm. Am J Med. 2013;126(9-1):10-20.

5. Cahn A, Cefalu WT. Clinical Considerations for Use of Initial Combination Therapy in Type 2 Diabetes. Diabetes Care. 2016;39(2):137-45.

6. Kim MK, Rhee EJ, Han KA. Efficacy and safety of teneligliptin, a dipeptidyl peptidase-4 inhibitor, combined with metformin in Korean patients with type 2 diabetes mellitus: 16 weeks, randomized, double-blind, placebo-controlled phase III trial. Diabetes Obes Metab. 2015;17(3):309-12.

7. Ghosh S, Trivedi S, Sanyal D, Modi KD, Kharb S. Teneligliptin real-world efficacy assessment of type 2 diabetes mellitus patients in India (TREAT-INDIA study). Diabetes Metab Syndr Obes. 2016;9:347-53.

8. Sharma SK, Panneerselvam A, Singh KP, Parmar G, Gadge P, Swami OC. Teneligliptin in management of type 2 diabetes mellitus. Diabetes Metab Syndr Obes. 2016;9:251-60.

Cite this article as: Dange SV, Narkar NS, Rane P, Das S, Madrewar V, Kothari R. Comparison of teneligliptin with sitagliptin as an add on to metformin in patients of type 2 diabetes mellitus: an observational study. Int J Basic Clin Pharmacol 2020;9:934-6. 